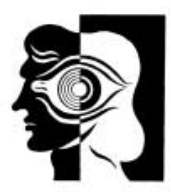

\title{
the columns
}

\section{correspondence}

\section{Cost of locum consultants}

Sir: I am writing to ask whether there are any other clinical or medical directors in psychiatry that are facing problems concerning the cost of using locum consultants.

I am the Medical Director of Mental Health Services in Herefordshire and, like many parts of the country, we are having considerable difficulty in appointing substantive consultants to vacant posts. We have two current vacancies and although we have advertised on a number of occasions we have not been able to attract applicants. I am aware that this is a national problem, and not just in mental health.

As we are unable to obtain substantive appointments we have to rely on using locums from various agencies. A locum consultant is paid an hourly rate rather than a salary, which would apply to a substantive appointment. As we have to provide a 1 in 5 consultant rota, our locums are being paid at an annual salary of $f 190000$ /year. This is over twice as much as a substantive consultant post. I have recently heard that one of the locum agencies was actually expecting a locum to be paid an hourly rate that would give $\mathrm{him} /$ her a salary equivalent of $\mathrm{f} 232 \mathrm{000}$ / year, roughly three times a substantive consultant salary.

Although a number of the locums we have had in the past have been very good, I am afraid some of them have been of sub-standard quality and nearly all of the complaints we have had about our mental health service in the last few years have been regarding locum appointments. Some of the locums we have appointed have either not got enough qualifications to obtain a substantive post, have retired, or, for physical health reasons, are unable to be appointed to substantive posts. We have even had situations where people have applied for locum consultant posts who have not been through specialist registrar training and are, therefore, less qualified than some of the trainees that we currently have working with us. Locum consultants also often play no, or very little, part in teaching, have considerably reduced administration responsibilities and often play no part in the development of services and all of the other aspects of consultant work that would be provided by a substantive appointment. They usually just provide a pure clinical input.

I realise that Herefordshire is not alone with this problem and from informal discussions I have had with a number of other medical directors in surrounding trusts, they are facing similar problems. I am really concerned that it can only be a matter of time before some of my substantive colleagues resign their post and offer to return to work as locums at twice their current salaries and with none of the teaching, administrative or other responsibilities.

I have raised this issue with the Secretary of State for Health but as yet have not received a reply from the department. I would be very interested to know if other mental health departments are facing similar problems and, if so, whether they would be willing to allow me to provide further information to the Department of Health to highlight this problem.

ChrisThomas Consultant Psychiatrist and Medical Director, Herefordshire Mental Health Services, Stonebow Unit, County Hospital, Hereford, HR1 2 ET

\section{Ambiguity of the Mental Health Act?}

Sir: Ogundipe et al conclude that there is perceived ambiguity in the legality of transferring people from one place of safety to another under Section 136 of the Mental Health Act (MHA) 1983 (Psychiatric Bulletin, October 2001, 25 388-390)

The MHA Commission in its Sixth Biennial Report states ". . . it is illegal to move the subject from one place of safety to another once assessment has been instigated" (p. 78). However, it does not cite case law or statute to support this view.

Section 136 of the MHA on a literal reading states nothing at all about transferring persons between places of safety. Indeed, the draftsman has written the language in the singular, not the plural. He uses the terms "a person" and "a place of safety". The issue of transfer is simply not raised at all. This being the case, I submit that Parliament never intended for persons to be transferred under the authority of this Section. If it did, it would have said so.

The Mental Health Act Commission. Sixth Biennial Report 1993-1995. London: HMSO.

Rafiq Memon Specialist Registrar in Forensic Psychiatry, Reaside Clinic, Birmingham Great Park, Bristol Road South, Rubery, Birmingham B45 9BE

\section{Government proposals for Mental Health Act require redesigning}

Sir: The current proposals for Mental Health Act reform (Department of Health, 2000) appear to have met with widespread concern from old age psychiatrists. Burton (2001) has perhaps expressed the concern more clearly than most. But the proposal that all those with long-term mental incapacity should have a care plan that is reviewed by a second opinion doctor seems bound to bring deep foreboding to those who work in the field.

It is certainly the case that the lack of safeguards highlighted by the Bournewood case give cause for concern ( $R v$ Bournewood, 1998) and that there is an absolute need for effective measures to be available that prevent abuse. However, before agreeing to use a safeguard procedure on all patients with long-term incapacity we should at least consider likely effects. Given the large numbers of patients in residential and nursing homes with incapacity, it must be clear that if the current proposals become law, then the time taken to produce care plans and get second opinions look set to outstrip the entire availability of old age psychiatry in the UK. Moreover, and perhaps more importantly, we know that the more rare a positive finding on a screening system, the more stringent is the screening method required to avoid missing a positive case. In long-term incapacity, we 